Though prognosis in terms of death was not statistically significantly correlated with $\mathrm{PO}_{2}$ in the overall analysis, there were associations between low $\mathrm{PO}_{2}$ and depressed level of consciousness, and between depressed level of consciousness (especially coma) and the more severe disturbances of respiratory pattern. This accords with the experience of Marquarsdsen (1969), who found "stertorous breathing and Cheyne-Stokes respiration" to be "almost as ominous as deep coma," attributing this to the frequent association of respiratory abnormalities with coma. These findings can be explained only in terms of additional pulmonary or cardiac pathology, possibly some degree of hypostatic pneumonia in the comatose patients, even though those with clinically or radiologically obvious consolidation were excluded. It seems improbable that coma per se was responsible for the hyperventilation since under most other circumstances coma is associated with hypoventilation. The mechanisms responsible for the hyperventilation are discussed elsewhere (Lane et al., 1971).

A high proportion of patients in whom it could be assessed showed post-hyperventilation apnoea. This is in keeping with the findings of Plum et al. (1962), who found this phenomenon in $90 \%$ of patients with bilateral supramedullary brain disease. In normal conscious man post-hyperventilation apnoea is seen only rarely, but can be induced by anaesthesia. It seems that cerebral damage and anaesthesia release the respiratory regulatory apparatus from the control of higher centres and that this leads to instability of $\mathrm{CO}_{2}$ control mechanisms. It is likely that this instability is one of the neurogenic defects which predis- pose to periodic breathing (Plum, 1966) and this is borne out by the frequent occurrence of periodic or Cheyne-Stokes breathing patterns following a short period of hyperventilation in the present series.

We wish to thank the physicians of the Radcliffe Infirmary for allowing us to study patients under their care, and the technicians of the Nuffield Department of Anaesthetics for their skilled assistance. One of us (D.J.L.) is in receipt of a grant from the Nuffield Committee for the Advancement of Medicine.

\section{References}

Cheyne, J. (1818). Dublin Hospital Reports, 2, 216

Gowers, W. R. (1893). A Manual of Diseases of the Nervous System, 2nd ed., p. 410. London, Churchill.

Hahn, C. E. N. (1969). Fournal of Scientific Instruments, Series 2, 2, 48.

Hurwitz, L. J., Groch, S. N., Wright, I. S., and McDowell, F. H. (1959). Archives of Neurology, 1, 491 .

Kelman, G. R., and Nunn, J. F. (1966). Fournal of Applied Physiology, 21, 1484.

Lane, D. J., Rout, M. W., and Williamson, D. H. (1970). British Medical

Marquardsen, J. (1969), Acta Neurologica Scandinavica, 45, Suppl. No. 38. Oppenheim, H. (1900). Disease of the Nervous System, p. 509. Philadelphia, Lippincott.

Plum, F. (1966). In Breathlessness, ed. J. B. L. Howell, and E. J. M. Campbell. $\mathrm{p}$. 203. Oxford, Blackwell.

Plum, F., Brown, H. W., and Snoep, E. (1962). Fournal of the American Medical Association, 181, 1050.

Steegman, A. T. (1951). Fournal of Nervous and Mental Disorders, 114, 35

Walsh, L. (1966). Proceedings of the Association for Research in Nervous and Mental Diseases, 41, 145.

\title{
Mechanism of Hyperventilation in Acute Cerebrovascular Accidents
}

\author{
D. J. LANE, M. W. ROUT, D. H. WILLIAMSON
}

British Medical fournal, 1971, 3, 9-12

\section{Summary}

Lumbar cerebrospinal fluid and arterial blood acid-base state were assessed in 19 patients within 24 hours of an acute cerebrovascular accident. Those with haemorrhage into the C.S.F. showed a lower C.S.F. pH and higher C.S.F. lactate than those without haemorrhage but the $\mathrm{PCO}_{2}$ was similar in the two groups, suggesting that this greater C.S.F. acidity was not responsible for a greater degree of hyperventilation. In those without haemorrhage an inverse relation was found between C.S.F. pH and arterial $\mathrm{PCO}_{2}$, suggesting that a nonchemical ventilatory drive-for example, due to central neurological damage-was responsible for the acid-base changes observed.

\section{Introduction}

Froman and Crampton-Smith (1966) described hyperventilation associated with C.S.F. acidosis in subarachnoid haemorrhage.

Nuffield Departments of Medicine and Anaesthetics and the Metabolic Research Laboratory, the Radcliffe Infirmary, Oxford bolic Resea

D. J. LANE, D.M., M.R.C.P., Lecturer

D. J. LANE, D.M., M.R.C.P., Lecturer
M. W. ROUT, M.B., M.R.C.P.ED., Senior Registrar (Present address: St. Mary's Hospital, Bury St. Edmunds)

D. H. WILLIAMSON, D.M., D.PHIL., M.R.C. External Staff

They attributed this acidosis to an increased lactate content in the C.S.F. and postulated from in-vitro studies that the lactate had originated from red cell metabolism (Froman and CramptonSmith, 1967). However, hyperventilation may also occur in neurological conditions when there is no blood in the C.S.F. Plum and Swanson (1959), investigating patients with acute brain stem disease exhibiting hyperventilation, ascribed this to a central neurogenic drive. Furthermore, hyperventilation per se causes a rise in C.S.F. lactate in experimental animals (Leusen and Demeester, 1966).

We have recently shown that hyperventilation carries a poor prognosis in patients with acute cerebrovascular accidents (Rout et al., 1971). The present study was designed to investigate the cause of this hyperventilation. It reports measurements of C.S.F. and arterial blood acid-base state in patients with acute cerebrovascular accidents and relates these measurements to the presence or absence of blood in the lumbar subarachnoid space.

\section{Methods}

Nineteen patients were studied within 24 hours of the onset of an acute cerebrovascular accident. At the time of lumbar puncture performed for diagnostic purposes a sample of C.S.F. was collected anaerobically for acid-base measurements. Simultaneously, a sample of arterial blood was withdrawn from the brachial artery by stab puncture. Five millilitres of the blood and $2 \mathrm{ml}$ of the C.S.F. were added to $5 \mathrm{ml}$ of $10 \%(\mathrm{w} / \mathrm{v})$ perchloric acid. 
$\mathrm{PCO}_{2}$ and $\mathrm{pH}$ in the arterial blood and C.S.F. and $\mathrm{Po}_{2}$ in blood were measured with standard Radiometer electrodes as described previously (Rout et al., 1971). Measurements on the C.S.F. required considerable care; the precautions taken have been discussed elsewhere (Lane et al., 1970).

The samples in perchloric acid were stored in ice and, after removal of protein and neutralization with potassium hydroxide, were analysed by enzymatic methods for lactate, pyruvate (Hohorst et al., 1959), and acetoacetate in 16 patients and 3hydroxybutyrate in 15 patients (Williamson et al., 1962). The sum of the values of these four acids was termed the total organic acidity.

\section{Results}

The data have been analysed in terms of the presence or absence of blood in the C.S.F. The term "haemorrhage" as applied to a C.S.F. sample or patient indicates the presence of red blood cells in the lumbar C.S.F. The term "infarct" is applied when the lumbar C.S.F. sample did not contain red blood cells.

The degree of hyperventilation as expressed by the reduction in $\mathrm{PCO}_{2}$ or the rise in arterial $\mathrm{pH}$ compared with normal values was similar in the two groups $(P>0.05$, see Table) but C.S.F. pH was significantly lower in those with haemorrhage $(P<0.005$, see Table and Fig. 1). This was associated with higher lactate and pyruvate concentrations (Fig. 1) and higher total organic

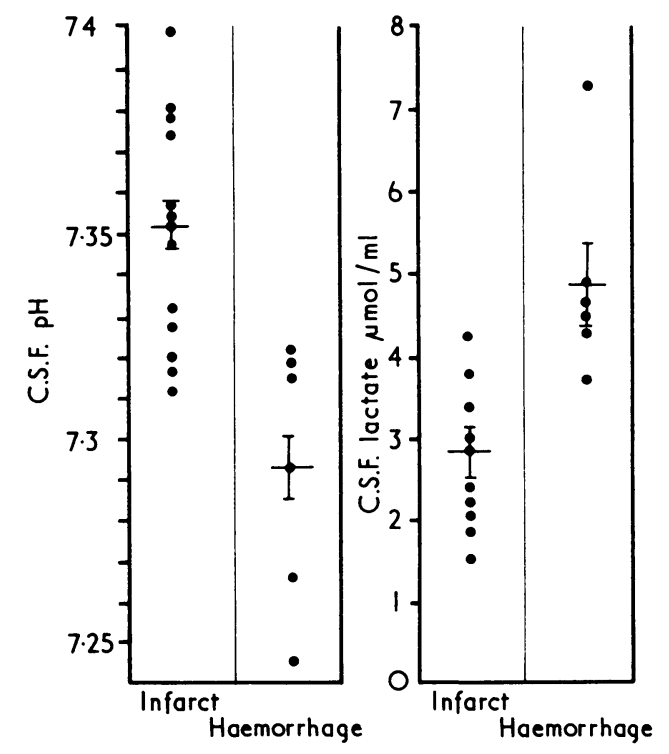

FIG. $1-$ C.S.F. pH and C.S.F. lactate in the patients studied. showing a more acid C.S.F. pH and a higher lactate concentration in those with blood in the lumbar C.S.F. (haemorrhage) compared with those without blood (infarct). Means and standard errors of means are indicated. acidity and higher lactate/pyruvate ratio in the C.S.F. of those with haemorrhage (see Table). Mean values for C.S.F. 3hydroxybutyrate and acetoacetate were not significantly higher in patients with haemorrhage (see Table).

Lactate and pyruvate were invariably higher in the C.S.F. than in arterial blood, showing C.S.F./blood ratios of 1.9 to 6.6 (mean $3.1 \pm 1.2$ ) for lactate and 1.4 to 3.6 (mean $2.2 \pm 0.8$ ) for pyruvate. The ratios were generally higher in patients with haemorrhage. By contrast, C.S.F. 3-hydroxybutyrate was higher than that in the blood in only two patients (ratios 1.30 and 1.14). One of these patients was diabetic but had low absolute values for ketone bodies (total $0.218 \mu \mathrm{mol} / \mathrm{ml}$ ); the other, who had high absolute levels of ketone bodies, was not diabetic. The mean C.S.F./blood 3-hydroxybutyrate ratio was $0.46 \pm$ $0 \cdot 36$. C.S.F. acetoacetate was invariably less than that in arterial blood (ratios C.S.F. to blood of 0.09 to 0.94 , mean $0.37 \pm 0.27$ ). There was no difference in terms of C.S.F./arterial blood ratios for 3-hydroxybutyrate or acetoacetate between patients with haemorrhagic and non-haemorrhagic strokes. Ketone bodies contributed little to total organic acidity in the C.S.F. in most patients $(0.6$ to $6.9 \%)$ but in one instance of haemorrhage made up $25.8 \%$ of the total acidity.

C.S.F. lactate and total organic acidity were also higher than normal in patients with infarct, and hyperventilation, as reflected in a lowered $\mathrm{PCO}_{2}$, was correlated with a raised C.S.F. lactate whether this was associated with haemorrhage or infarct (Fig. 2). The correlation coefficient for the combined data from all subjects was $r=0.61(P<0.02)$.

Despite the raised organic acids seen in nearly all the C.S.F. samples examined, acidity in terms of a C.S.F. pH less than

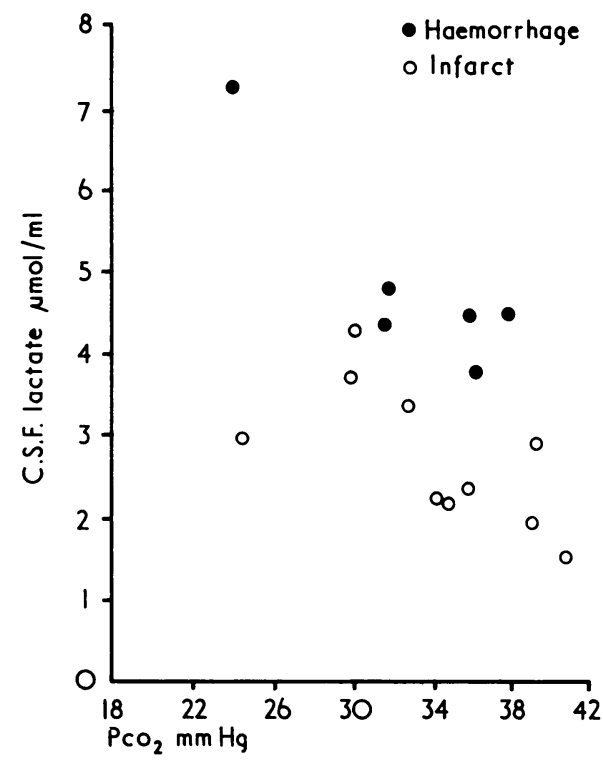

FIG. 2-C.S.F. lactate compared with $\mathrm{PCO}_{2}$.

\begin{tabular}{|c|c|c|c|c|c|c|c|c|}
\hline & \multicolumn{3}{|c|}{ Haemorrhagic Lumbar C.S.F. } & \multicolumn{3}{|c|}{ No Blood in Lumbar C.S.F. } & \multicolumn{2}{|c|}{$\begin{array}{l}\text { Significance of Difference } \\
\text { between Groups }\end{array}$} \\
\hline & Arterial Blood & C.S.F. & No. & Arterial Blood & C.S.F. & No. & $\begin{array}{c}\text { Arterial } \\
\text { Blood }\end{array}$ & C.S.F. \\
\hline 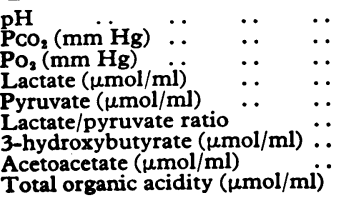 & $\begin{array}{l}7.441 \pm 0.061 \\
32.7 \pm 5.0 \\
69.6 \pm 10.8 \\
1 \cdot 29 \pm 0.56 \\
0.11 \pm 0.04 \\
12.4 \pm 4.2 \\
0.58 \pm 0.46 \\
0 \cdot 24 \pm 0.16 \\
2.30 \pm 0.64\end{array}$ & $\begin{array}{l}7.294 \pm 0.031 \\
40.6 \pm 2.0 \\
4.88 \pm 1.41 \\
0.28 \pm 0.08 \\
17.9 \pm 2.7 \\
0.15 \pm 0.11 \\
0.09 \pm 0.13 \\
5.59 \pm 1.52\end{array}$ & $\begin{array}{l}6 \\
6 \\
6 \\
6 \\
6 \\
6 \\
6 \\
6 \\
6\end{array}$ & $\begin{array}{l}7.451 \pm 0.052 \\
33.4 \pm 5.8 \\
71.7 \pm 4.9 \\
1.07 \pm 0.38 \\
0.10 \pm 0.04 \\
8.9 \pm 5.5 \\
0.27 \pm 0.24 \\
0.15 \pm 0.10 \\
1.54 \pm 0.63\end{array}$ & $\begin{array}{l}7.354 \pm 0.035 \\
39.8 \pm 5.8 \\
2.78 \pm 0.85 \\
0.18 \pm 0.04 \\
15.3 \pm 2.2 \\
0.08 \pm 0.06 \\
0.05 \pm 0.02 \\
2.97 \pm 0.96\end{array}$ & $\begin{array}{r}13 \\
13 \\
13 \\
10 \\
10 \\
10 \\
9 \\
10 \\
9\end{array}$ & $\begin{array}{l}\text { N.S. } \\
\text { N.S. } \\
\text { N.S. } \\
\text { N.S. } \\
\text { N.S. } \\
\text { N.S. } \\
\text { N.S. } \\
\text { N.S. } \\
\text { P }<0.01\end{array}$ & $\begin{aligned} P & <0.005 \\
\text { N.S. } & \\
P & <0.002 \\
P & <0.005 \\
0.02 & <P .<0.05 \\
\text { N.S. } & \\
\text { N.S. } & \\
P & <0.002\end{aligned}$ \\
\hline
\end{tabular}


normal was seen in only three patients. These three showed haemorrhage into the lumbar C.S.F. and a lowered $\mathrm{PCO}_{2}$. In all other patients C.S.F. pH was normal or more alkaline than normal, and within the group designated infarct there was a clear negative correlation between C.S.F. $\mathrm{pH}$ and $\mathrm{PCO}_{2}$; those patients with a low $\mathrm{PCO}_{2}$ had an alkaline C.S.F. pH (Fig. 3). The correlation coefficient for the data from patients with infarcts in Fig. 3 was $\mathbf{r}=0.86(P<0.001)$.

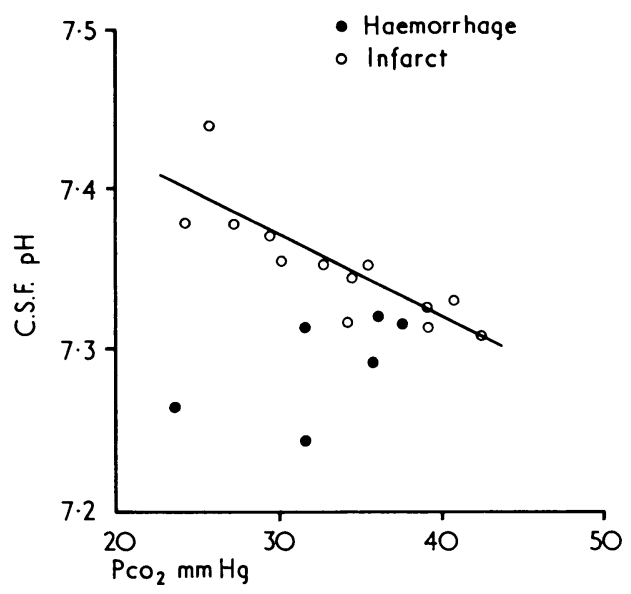

FIG. 3-C.S.F. pH compared with $\mathrm{PcO}_{2}$ showing a significant $(\mathrm{P}<0.001)$ negative correlation in patients having no blood in the lumbar C.S.F. (infarct), with those showing a haemorrhagic C.S.F. (haemorrhage) having a more acid C.S.F. $\mathrm{pH}$ at reduced levels of $\mathrm{PCO}_{2}$

\section{Discussion}

There are three possible mechanisms for hyperventilation in association with an acute cerebrovascular accident: (1) an hypoxic drive, (2) a C.S.F. acidosis, and (3) a central neurogenic drive.

\section{HYPOXIA}

Haldane observed that significant ventilatory stimulation occurred with hypoxia only when inspired oxygen had dropped to around $14 \%$ (Haldane and Poulton, 1908). This represents a $\mathrm{Po}_{2}$ of about $50-60 \mathrm{~mm} \mathrm{Hg}$. Hypoxic sensitivity varies greatly between individuals, but since there was no correlation between $\mathrm{Po}_{2}$ and $\mathrm{PCO}_{2}$ in the patients studied and only one patient had a $\mathrm{PO}_{2}$ of less than $60 \mathrm{~mm} \mathrm{Hg}$, it would seem unlikely that hypoxia was an important cause of hyperventilation in these patients with acute cerebrovascular disorders. It might, however, potentiate the effect of other respiratory stimuli.

\section{C.S.F. ACIDOSIS}

Leusen (1954) demonstrated in dogs that perfusion of the ventriculo-cisternal system with mock C.S.F. of increased acidity or raised $\mathrm{PCO}_{2}$ led to ventilatory stimulation. Further work by Mitchell et al. (1963) led to the location in cats of chemosensitive areas, thought to be responsible for this phenomenon, on the lateral surface of the medulla. These receptors undoubtedly play a part in normal ventilatory regulation and may contribute up to $60 \%$ of the normal respiratory drive by responding to acid-base changes in the cisternal C.S.F. (Lambertsen et al., 1965).

In this study C.S.F. has been sampled from the lumbar space. The acid-base characteristics of this fluid may not reflect accurately the characteristics of cisternal C.S.F. during acute acid-base disturbances (Fisher and Christianson, 1963) though there seems to be good agreement during chronic disturbances (Bradley et al., 1965). The present studies were carried out within 24 hours of the onset of an acute cerebrovascular accident. While it is evident that the patients would not be in a chronic steady state at this time, it seems likely that disequilibrium between lumbar and cisternal fluids would have settled since animal studies have shown equality in $\mathrm{pH}$ between samples taken from these two sites at half to one hour after an acute ventilatory change (Plum and Posner, 1968).

Previous studies in this field have measured the contributions of lactate and pyruvate towards C.S.F. acidity but not the contributions of ketone bodies. The present data show that in most instances this is not important. Occasionally, however, a significant proportion of total organic acidity may be attributable to 3-hydroxybutyrate or acetoacetate. The lower values of these acids in the C.S.F. compared with the arterial blood may reflect cerebral tissue utilization of ketone bodies (Owen et al., 1967) or imperfect penetration of the blood-brain barrier. Since the contributions of pyruvate, 3-hydroxybutyrate, and acetoacetate to total organic acidity were small and not significantly different in patients with a haemorrhagic C.S.F. from those without haemorrhage, further discussion is confined to a consideration of lactate changes.

The finding of an increased C.S.F. acidity associated with increased lactate content in patients with haemorrhage into the subarachnoid space led to the hypothesis that hyperventilation in these patients might be due to the presence of blood causing a C.S.F. lactic acidosis (Froman and Crampton-Smith, 1966, 1967). Though some of the patients in the present series had a C.S.F. $\mathrm{pH}$ more acid than normal in association with haemorrhage into the subarachnoid space, others with haemorrhage and an increased C.S.F. lactate content had a normal C.S.F. pH. Since there was no difference in $\mathrm{PCO}_{2}$ between the groups with haemorrhage and infarct we can conclude that though the C.S.F. $\mathrm{pH}$ of the haemorrhagic group was more acid than in the nonhaemorrhagic group there was no greater tendency to hyperventilation. The data in Fig. 2 even suggest that a given C.S.F. lactate level was associated with less hyperventilation (higher $\mathrm{PCO}_{2}$ ) in those with haemorrhage than in those without.

This conclusion is supported by the observations of Posner et al. (1968), who examined C.S.F. and blood acid-base state in 29 patients with spontaneous subarachnoid haemorrhage. In 20 who were hyperventilating (arterial $\mathrm{pH}>7 \cdot 45 ; \mathrm{PCO}_{2}<35$ ) the mean C.S.F. pH was only slightly acid (7.302) though their mean lactate content was $6.7 \mu \mathrm{mol} / \mathrm{ml}$. In nine patients not hyperventilating the mean C.S.F. pH was more acid $(7 \cdot 267)$ but C.S.F. lactate was lower $(3.7 \mu \mathrm{mol} / \mathrm{ml})$.

\section{NEUROGENIC DRIVE}

An increase in C.S.F. lactate was also seen in patients in this series with acute cerebrovascular accidents but no haemorrhage into the C.S.F. Normal values for lumbar C.S.F. lactate given by Pontén et al. (1968) were $1.28-1.86 \mu \mathrm{mol} / \mathrm{ml}$, with a mean of $1 \cdot 62 \pm 0 \cdot 18$. This range was exceeded by all but one of the 16 patients in whom lactate was measured. Leusen and Demeester (1966) showed that hyperventilation itself leads in experimental animals to an increase in C.S.F. lactate. It is therefore possible that the inverse correlation found between $\mathrm{PCO}_{2}$ and C.S.F. lactate in the present series was not due to the C.S.F. lactic acidosis causing hyperventilation and a reduced $\mathrm{PCO}_{2}$ but to hyperventilation from some other source causing a reduced $\mathrm{PCO}_{2}$ and so a rise in C.S.F. lactate.

The presence of a neurogenic drive could satisfy these latter conditions as a cause of hyperventilation. If this were so there would be predictable changes in the C.S.F. $\mathrm{PCO}_{2}$ and pH. The fall in $\mathrm{PCO}_{2}$ consequent on the neurogenic drive would be associated with a similar fall in C.S.F. $\mathrm{PCO}_{2}$. In the acute phase before full compensation had taken place, C.S.F. pH would become alkaline. Our results show that in non-haemorrhagic strokes there was a statistically significant relationship between 
$\mathrm{PCO}_{2}$ and C.S.F. pH in a direction predicted for such a neurogenic drive-namely, a relatively alkaline C.S.F. $\mathrm{pH}$ associated with a reduced $\mathrm{PCO}_{2}$.

The patients with C.S.F. haemorrhage showed a more acid C.S.F. at any given $\mathrm{PCO}_{2}$ when compared with the non-haemorrhagic (Fig. 3). This increased acidity is presumably due to the presence of additional lactate and pyruvate consequent on the presence of blood in the subarachnoid space, but this does not apparently lead to any greater hyperventilation than might be caused by the postulated neurogenic drive. The data of Posner et al. (1968) also support the suggestion that a neurogenic drive is important in patients with haemorrhage into the C.S.F. in that the patients exhibiting hyperventilation had a normal rather than an acid C.S.F. pH despite the presence of higher C.S.F. lactate concentrations.

\section{Conclusion}

It is suggested that in most instances of hyperventilation in acute cerebrovascular disease a neurogenic drive is responsible. The presence of blood in the subarachnoid space and the associated rise in C.S.F. lactate may contribute towards the total ventilatory drive when the C.S.F. $\mathrm{pH}$ becomes more acid than normal, but even under these circumstances much of the ventilatory drive still appears to originate from a neurogenic source.

We are grateful to the physicians of the Nuffield Department of Medicine for allowing us to study patients under their care. One of us (D.J.L.) wishes to thank the Nuffield Committee for the Advancement of Medicine for financial support. Professor A. Crampton-Smith was a constant source of encouragement and advice.

\section{References}

Bradley, R. D., Semple, S. J. G., and Spencer, G. T. (1965). fournal of Physiology, 179, 442.

Fisher, V. J., and Christianson, L. C. (1963). Fournal of Applied Physiology, 18,712 .

Froman, C., and Crampton-Smith, A. (1966). Lancet, 1, 780.

Froman, C., and Crampton-Smith, A. (1967). Lancet, 1, 965.

Haldane, J. S., and Poulton, E. P. (1908). Fournal of Physiology, 37, 390.

Hohorst, H. J., Kreutz, F. F., and Bucher, T. (1959). Biochemische Zeitschrit, 332, 18.

Lambertsen, C. J., Gelfand, R., and Kemp, R. A. (1965). In Cerebrospinal Fluid and the Regulation of Ventilation, ed. C. M. Brooks, F. F. Kao, Fluid and the Regulation of Ventilation, ed.

Lane, D. J., Howell, J. B. L., and Stretton, T. B. (1970). Clinical Science, 39,391 .

Leusen, I. R. (1954). American fournal of Physiology, 176, 39, 45.

Leusen, I., and Demeester, G. (1966). Archives Internationales de Physiologic et Biochimie, 74, 25.

Mitchell, R. A. Loeschcke, H. M., Massion, W. H., and Severinghaus, J. W. (1963). Fournal of Applied Physiology, 18, 523.

Owen, O. E., et al. (1967). Journal of Clinical Investigation, 46, 1589.

Plum, F., and Posner, J. B. (1968). Scandinavian fournal of Laboratory and Clinical Investigation, Suppl. No. 102, I:B.

Plum, F., and Swanson, A. G. (1959). Archives of Neurology and Psychiatry, 81,535 .

Pontén, U. Kjällquist, Å, Siesjö, B. K., Sundbärg, G and Svendgaard, N. (1968). Scandinavian fournal of Laboratory and Clinical Investigation (1968). Scandinavian

Posner, J. B., Plum, F., and Shapiro, W. R. (1968). Scandinavian fournal of Laboratory and Clinical Investigation, Suppl. No. 102, IX:B.

Rout, M. W., Lane, D. J., and Wollner, L. (1971). British Medical fournal, 3, 7 Williamson, D. H., Mellanby, J., and Krebs, H. A. (1962). Biochemical fournal, 82, 90 .

\title{
Epilepsy and Driving
}

\author{
R. D. H. MAXWELL, G. E. LEYSHON
}

British Medical fournal, 1971, 3, 12-15

\section{Introduction}

\section{Summary}

The status of the epileptic applicant for a licence to drive a private motor vehicle has changed from total prohibition through a stage of partial approval subject to medical assessment to the present conditional right to a driving licence. We report a study of a series of patients which shows that many and probably most epileptics have obtained driving licences by concealment of their condition, yet the new regulations continue to expect true declarations. It is suggested that, in common with applicants for a public service vehicle or a heavy goods vehicle driving licence, the applicant for a licence to drive a private motor vehicle should provide a medical report of fitness. The epileptic should be included in a general category of medically restricted drivers subject to individual medical assessment.

Pinderfields General Hospital, Wakefield R. D. H. MAXWELL, M.D., M.R.C.P.GLASG., Consultant-in-Charge, Department of Electrophysiology

West Riding County Council Health Department, Wakefield G. E. LEYSHON, D.P.H., D.R.C.O.G., Principal Medical Officer
Symonds (1948) advocated that epileptics who had been free from attacks for a specified period should be able to state a case for being granted a licence to drive. He based his opinion on the fact that much more had become known about epilepsy, especially from electroencephalography and from new and effective drug therapy. Suppression of seizures had become possible, and the policy of an absolute bar to driving was difficult to sustain because cases differed in aetiology and prognosis.

The acceptance of a more liberal viewpoint was slow, however, Schnitker (1963) recorded that in some parts of the United States an epileptic could get a licence to drive provided a physician stated that he would never have an epileptiform seizure. In Great Britain the view of Hierons (1956), that the liability to seizures was very small in a patient who had been free from them for three years while on medication and for another two years after discontinuing medication, met with a wide measure of medical approval. In 1964 a London stipendiary magistrate ruled that because a driver was being treated with anticonvulsant drugs it did not mean he was suffering from epilepsy. It was the difficulty of defining both legally and medically the meaning of "suffering" which prompted the Ministry of Transport to state in a memorandum in 1961: "In any case of doubt as to whether an applicant for a driving licence, or the holder of a driving licence, is debarred from holding a licence by reason that he is suffering from epilepsy, the licensing authority will, no doubt, consult the local county or county 